\title{
ANÁLISIS DE LA FUNDACIÓN DEL EZLN EN CHIAPAS DESDE LA PERSPECTIVA DE LA ACCIÓN COLECTIVA INSURGENTE
}

\author{
Adela Cedillo-Cedillo
}

Resumen: El objetivo de este artículo es analizar los elementos que originan la acción colectiva insurgente tomando como referente el caso de la fundación del Ejército Zapatista de Liberación Nacional (EZLN) en 1983. A través de la reconstrucción del proceso formativo de las FLN-EZLN se cuestionan las interpretaciones estructuralistas y se enfatiza el juego dinámico de los factores estructurales, coyunturales, organizacionales y subjetivos. Se plantea que el éxito inicial de la convocatoria de los guerrilleros entre comunidades indígenas de las regiones Norte y Cañadas se debió al agotamiento de otras ofertas políticas para resolver las demandas de lucha por la tierra y a la necesidad campesina de autodefensa, motivada por la represión y la amenaza de desalojo masivo de la Selva Lacandona. La metodología empleada para este estudio fue tanto cualitativa como de investigación documental.

Palabras clave: neozapatismo, guerrillas, campesinos, indígenas, autodefensa.

Enviado a dictamen: 26 de junio de 2012

Aprobación: 20 de julio de 2012

Revisiones: 1

Mtra. Adela Cedillo Cedillo, maestra en Estudios Latinoamericanos por la UNAM. Temas de especialización: guerra fría en América Latina; historia de la izquierda y movimientos armados de la segunda mitad del siglo Xx en México.

Correos electrónicos: adel79@yahoo.com; liebekrieg@gmail.com.
Abstract: The purpose of this paper is to examine the factors underlying insurgent collective action in the founding of the Zapatista Army of National Liberation (EZLN) in 1983. Through the reconstruction of the FLN-EZLN's formative process this paper challenges structuralist interpretations and emphasizes the dynamic interplay of structural, conjunctural, organizational and subjective factors. I argue that the success in creating a guerrilla movement within indigenous communities in the North and Cañadas regions was due to the exhaustion of other political propositions to resolve land issues and the need for peasant self-defense, motivated by repression and threat of mass eviction of the Lacandon Jungle. The methodology used for this study was both qualitative and documentary research.

Keywords: neozapatismo, guerrillas, peasants, indigenous, self-defense.

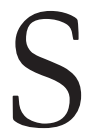
obre las causas del levantamiento armado del Ejército Zapatista de Liberación Nacional (EZLN) en 1994 se han escrito numerosos artículos, ensayos y libros, algunos de los cuales extrapolan los mismos argumentos a la fundación del EZLN en 1983 sin distinguir que se trata de dos coyunturas diferentes. Esto se debe, en buena medida, a la importancia que 
se le concede a las explicaciones estructurales, que se remontan a la época de la conquista española (el despojo territorial de los indígenas, su explotación y subordinación política, sus condiciones de pobreza y marginalidad extremas, etcétera). De acuerdo con esta interpretación, este orden opresivo es la causa por la que los indígenas se han sublevado una y otra vez a lo largo de la historia y lo seguirán haciendo hasta emanciparse por completo (véase un ejemplo de ello en González Casanova, 1995).

El objetivo de este artículo es evidenciar que los factores estructurales no fueron la causa directa de la fundación del EZLN en Chiapas, cuestionar la interpretación teleológica de los indígenas como un sujeto esencialmente rebelde y hacer luz sobre otros aspectos que por lo general se soslayan, pero que tienen un gran potencial explicativo para entender las dinámicas de la acción colectiva insurgente, tales como los marcos interpretativos, la competencia por la hegemonía cultural, la existencia de redes sociales altamente cohesionadas reconvertidas en redes políticas y la correlación entre violencia de Estado, radicalización y el surgimiento de un sentido de autodefensa. Asimismo, describiré las especificidades del contexto en el que se formó el EZLN, partiendo del supuesto de que los episodios de 1983 y 1994 son dos momentos que, si bien pertenecen al mismo proceso, son completamente distintos.

Mientras abundan los análisis teóricos sobre revueltas, rebeliones y revoluciones, así como sobre violencia política y el llamado "terrorismo", no hay una reflexión robusta sobre movimientos armados que no entran en ninguna de las categorías anteriores, como sería el caso de un sinnúmero de organizaciones políticomilitares latinoamericanas, que han sido estudiadas de manera casuística o comparativa, pero sin un marco teórico general. ${ }^{1}$ De hecho, la dificultad para construir uno reside precisamente en la enorme diversidad de contextos y experiencias. Por consiguiente, no me propongo comprobar la utilidad de una teoría en particular, sino mostrar los instrumentos de análisis que he identificado como pertinentes al objeto de estudio.

En el terreno de lo empírico, una de las grandes omisiones de las obras que abordan la génesis del neozapatismo tiene que ver con la historia de las Fuerzas de Liberación Nacional (FLN), la organización matriz del EZLN a la que éste estuvo subordinado hasta enero de 1993. ${ }^{2}$ Las razones por las que las FLN han pasado desapercibidas obedecen en buena medida a la ruptura del EZLN con su pasado socialista, ${ }^{3}$ pero también a la incapacidad del Estado para desmantelar por completo a esta organización clandestina activa entre 1969 y 1992, lo que sin duda debe interpretarse como un enorme fallo respecto a su política de seguridad nacional. Sin embargo, es imposible entender el surgimiento y desarrollo del EZLN al margen de las FLN.

Las fuentes escritas para conocer la trayectoria de las FLN-EZLN entre 1969 y 1993 son muy escasas: una parte de la documentación, correspondiente al periodo que va de 1969 a 1980, se encuentra en el fondo de la Dirección Federal de Seguridad del Archivo General de la Nación; el resto está azarosamente repartido entre la Secretaría de Gobernación, la Secretaría de la Defensa y el EZLN, pero ninguna de estas tres colecciones está abierta a consulta pública. Del mismo modo, los viejos militantes de las FLN que permanecen en activo, o bien se han negado a conceder entrevistas, o lo han hecho ofreciendo una imagen idealizada del grupo. Entre los cuadros desmovilizados hay mayor cautela aún, sobre todo entre quienes nunca fueron localizados por las fuerzas de seguridad. Si bien algunos de ellos muestran disposición a conceder entrevistas, respetan los pactos de silencio que hicieron con la organización.

En términos bibliográficos, algunos de los principales referentes sobre el tema son autores que han sobresalido tanto por su notable antizapatismo como por la facilidad con la que accedieron a las fuentes policiacas y militares, así como a testimonios de desertores del grupo cuando el conflicto atravesaba por un periodo crítico, como es el caso de Carlos Tello Díaz (1995), María del 
Carmen Legorreta Díaz (1998), Maité Rico y Bertrand de la Grange (1998). Autores más afines al neozapatismo han seguido las indicaciones del EZLN respecto a no profundizar en su historia bajo el argumento de que puede afectar su seguridad interna en un contexto en el que se mantiene la guerra de baja intensidad. ${ }^{4}$ No obstante, las revelaciones de los autores antizapatistas han sido contundentes en torno a diversos aspectos que el EZLNhubiera preferido mantener en secreto para no comprometer la seguridad de sus militantes, por lo que no resta más que discernir, dentro del volumen de información que se ha filtrado hasta el momento, qué puede considerarse valioso y verosímil, y qué es lo que debe ser contrarrestado con datos duros e interpretaciones que, al menos tentativamente, no estén cargadas hacia uno u otro bando. Para ello he utilizado un abanico de fuentes tales como comunicados, revistas y documentos internos de las FLN, así como entrevistas con exmilitantes que ocuparon cargos importantes dentro de la organización y con familiares de militantes ejecutados o desaparecidos. ${ }^{5}$ Existen aún muchos vacíos informativos, sin embargo, el material reunido es suficiente para ofrecer una idea comprehensiva sobre las condiciones en que las FLN fundaron EZLN en 1983. A manera de antecedentes, abordaré los aspectos principales del proceso formativo de las FLN.

\section{Causas de la formación de las FLN}

Durante las décadas de los sesenta y setenta del siglo XX el contexto internacional era propicio para la difusión de ideologías revolucionarias, ya que algunos ejércitos populares en Asia, África y América habían tomado el poder y habían derrotado al imperialismo extranjero. Desde la perspectiva actual, sería desmesurado comparar el proceso político de un país de las dimensiones de China con una isla como Cuba - aún cuando ambos eran declarativamente socialistas-, pero en los sesenta la interpretación más socorrida era que tarde o temprano todas las naciones transitarían por la misma ruta emancipatoria. Es innegable que, al margen de si había o no condiciones en los países subdesarrollados para impulsar movimientos de liberación nacional o revoluciones socialistas, estos ejemplos exitosos estimularon poderosamente las tentativas insurreccionales en muchos de ellos.

El hecho de que después de los sesenta, sólo de forma excepcional, alguna organización revolucionaria tomara el poder, es un indicador de que, contrariamente a lo que pensaban diversas corrientes de inspiración marxista de la época, las contradicciones entre la estructura y la superestructura capitalistas y las crisis del sistema no eran condiciones predeterminadas para la revolución mundial. La mayoría de organizaciones armadas no pudieron hacer una revolución, aún si contaban con amplio respaldo popular, y no había una ley histórica inexorable que prescribiera el fin del capitalismo en un plazo determinado.

Se pudieron haber conjugado las condiciones objetivas y subjetivas planteadas por el marxismoleninismo, pero no hay forma alguna de determinar si éstas habían madurado; en otras palabras, es imposible predecir una situación revolucionaria. ${ }^{6}$ La mayoría de los guerrilleros latinoamericanos tuvo una visión dogmática al respecto, ya que pensaban que las condiciones objetivas estaban dadas de forma permanente y las subjetivas se producirían a partir del despliegue de la violencia revolucionaria. En realidad, las complejas interacciones entre lo estructural, lo coyuntural, lo organizacional y lo subjetivo, fueron determinantes en el éxito de algunos proyectos revolucionarios y en el fracaso de otros. Tal vez debamos renunciar a la pretensión de encontrar un modelo para todos los casos y entender el juego dinámico de estos factores en cada país o región.

La influencia de los acontecimientos mundiales en la aparición de una oleada guerrillera en México no tiene un correlato en el orden económico sino en la difusión de las ideologías revolucionarias castro-guevarismo, maoísmo, marxismo vietnamita, 
etcétera-, avaladas por su éxito aparente, y elevadas al rango de verdades universales. Desde luego, no se trata de sobredimensionar la importancia del clima ideológico global, sino de entender su mediación entre las estructuras y los agentes. ${ }^{7}$ En lo interno, se puede observar que la crisis del desarrollismo a fines de los sesenta no tuvo tanta incidencia en la movilización social como las fallas inherentes a la estructura política, entre las que destacan el cierre del campo político a los opositores y la represión sistemática. ${ }^{8}$ Estos fenómenos fueron interpretados por las organizaciones armadas emergentes bajo la perspectiva de la lucha de clases y el combate al Estado burgués y represor. ${ }^{9}$

Las FLN se fundaron en 1969 en la ciudad de Monterrey, Nuevo León, como una organización político-militar de inspiración castroguevarista, cuyo fin era la toma del poder político para instaurar una república popular socialista. El fin de la década estuvo marcado por el décimo aniversario de la Revolución cubana, la resonancia de la guerra de liberación nacional de Argelia (1962), el desenvolvimiento de la guerra de Vietnam (iniciada en 1964) y el llamado que hiciera Ernesto Che Guevara en 1967 a "crear dos, tres... muchos Vietnam”, cumpliendo él mismo con tal consigna en Bolivia.

En México, el régimen autoritario, presidencialista y corporativo, emanado de la revolución de 1910, había sufrido su primer resquebrajamiento en 1968, cuando el movimiento estudiantil puso en entredicho la hegemonía del Partido Revolucionario Institucional (PRI) y el gobierno respondió con un incremento del terror como política de Estado argumentando la defensa de la seguridad nacional.

Elperiodo de terror estatal, que va aproximadamente de 1964 a 1982, ha sido caracterizado convencionalmente como la "guerra sucia". No obstante, hay que admitir que no toda la izquierda fue perseguida con el mismo encono: el ala moderada, aunque semilegal, se mantenía dentro de los márgenes del sistema bajo la promesa de formar parte de los procesos electorales; el ala radical era relativamente tolerada, aunque el Estado tendió a reprimir las muestras más acabadas de la organización obrera y campesina independiente, en cambio, la ultraizquierda fue prácticamente erradicada (Rivas Ontiveros, 2007; Cedillo y Gamboa, 2010). En ese contexto, en 1974 las FLN fueron objeto de un vasto operativo contrainsurgente que las redujo drásticamente y las condujo a un prolongado repliegue.

En otros estudios he abordado los pormenores de la formación de las FLN, su perfil político-ideológico, su estructura organizativa, su estrategia y táctica militar, la composición de clase de sus militantes, sus principales acciones, sus vínculos internacionales y las trayectorias individuales de sus dirigentes y cuadros medios (Cedillo, 2008, 2010; Calderón y Cedillo, 2012). Lo que me interesa destacar ahora es el análisis de las causas de la formación del grupo como antesala al mismo debate respecto al EZLN.

Recapitulando, hay un primer elemento explicativo, que se asocia a la esfera cognitiva e ideal-valorativa, y que algunos teóricos engloban bajo la categoría de procesos de enmarcado entendidos como: los "esfuerzos estratégicos conscientes realizados por grupos de personas... [para] forjar formas compartidas de considerar el mundo y a sí mismas que legitimen y muevan a la acción colectiva" (McAdam, McCarthy y Zald, 1999: 31). Sin embargo, si algo caracteriza a los procesos de enmarcado es que su impacto en los individuos es diferenciado. ¿De qué depende que ciertas ideologías e imaginarios interpelen la subjetividad de algunos individuos y de otros no, estando unos y otros en condiciones similares? Más aún, ipor qué dentro de quienes comparten la misma ideología unos son espectadores y otros actores sociales?

Una posible respuesta es que ambas situaciones dependen de la significación colectiva del entorno que se genera al interior de las redes de pertenencia, lo que la sociología de la acción colectiva define como las estructuras de movilización. Éstas comprenden "los canales colectivos formales e informales a través 
de los cuales la gente puede movilizarse e implicarse en la acción colectiva" (McAdam, McCarthy y Zald, 1999: 24). Los primeros tienen que ver, por ejemplo, con organizaciones profesionales del movimiento social, mientras que los segundos corresponden a entornos básicos tales como redes de familiares, vecinos, amigos o compañeros de trabajo. De este modo, en el caso que nos ocupa, un individuo que compartiera la ideología revolucionaria pero no perteneciera a una red que promoviera la lucha armada, difícilmente podía sumarse a ella, máxime por el sistema de espionaje y control que permeaba casi toda la sociedad. En cambio, una persona sin antecedentes políticos podía, a través de sus redes informales, convertirse en colaboradora de la guerrilla.

Seis de los ocho fundadores de las FLN constituían un grupo de amigos que habían participado desde comienzos de la década de los sesenta en diversas iniciativas políticas dentro y fuera de la Universidad de Nuevo León. A través de estos proyectos lograron vincularse con militantes de otros grupos y hacerse de simpatizantes, a la vez que involucraron a familiares y amigos. Tras la fundación de las FLN, el pequeño grupo original pudo crecer por la manera exitosa en que convirtió sus redes preexistentes en estructuras de movilización para el proyecto político-militar..$^{10}$

Las organizaciones armadas de la época hicieron frente, no sólo a un enemigo al que identificaban como la burguesía y su Estado, sino también a la izquierda democrática que rechazaba tomar las armas. Asimismo, entre quienes compartían el mismo horizonte revolucionario se desató una competencia hegemónica. En sus escritos, las organizaciones rara vez aludían unas a otras, pero cada una se reivindicaba como la portadora de la única línea político-militar correcta (véanse distintos ejemplos al respecto en Oikión y García, 2006). De esta manera, pese a su profundo aislamiento, las FLN insuflaban en sus militantes el orgullo de pertenecer a la única organización capaz de llevar a cabo la segunda independencia de México.
Si bien el sectarismo, antes que la competencia explícita, fue uno de los sellos más característicos de los distintos grupos, cada uno se veía a sí mismo como la vanguardia que tomaría el poder y a la que tendrían que supeditarse todos los demás. Ahora bien, ¿de qué forma la lucha por la hegemonía ideológica estimulaba, la acción colectiva? La respuesta está en la creación de campos de identidad de protagonistas y antagonistas. Si como sugiere la teoría postmarxista, los individuos, no pelean únicamente a partir de su identidad de clase sino también a través de otras posiciones de sujeto (Laclau y Mouffe, 1986), habrá que admitir el valor estratégico de la identidad para la movilización. Tanto las identidades individuales como las colectivas se promueven en el proceso y se reafirman en la lucha (véase Hunt, Benford y Snow en Chihu, 2010).

Las variables consideradas hasta ahora pueden emplearse para analizar cualquier tipo de acción colectiva, pero la insurgente requiere, desde luego, tomar en cuenta los factores que conducen al radicalismo político. Así por ejemplo, pese a que antes del año 68 hubo organizaciones armadas, la escalada de la violencia contra movimientos civiles y pacíficos fue un factor muy importante en la radicalización de cientos de activistas del medio estudiantil, ya que generó un sentido de autodefensa que fue un parteaguas para decidir entre militar abiertamente o hacerlo desde la clandestinidad. Tal correlación entre violencia estatal y radicalismo también se puede observar en los movimientos campesinos de Chiapas, como veremos más adelante, si bien en ambos casos fue un fenómeno de minorías.

Las FLNfueron una organización original en múltiples aspectos y uno de los más notables fue la adopción de marcos interpretativos a largo plazo, impermeables a los cambios del entorno. La organización tuvo una base ideológica ecléctica, mezcla del nacionalismo revolucionario cardenista, el marxismo-leninismo, el castro-guevarismo, aspectos del maoísmo en su vertiente vietnamita y ciertos aportes de la teoría de la dependencia. El pensamiento político de las FLN desde 
sus inicios se puede condensar en los siguientes puntos extraídos de sus comunicados:

- El desarrollo de la lucha de clases conduce a un ciclo revolucionario ascendente.

- La nueva revolución mexicana es parte de la gran revolución latinoamericana que dará lugar a la gran patria latinoamericana.

- Las acciones represivas del enemigo imponen la vía armada como el único camino.

- La revolución se dará a través de una guerra de liberación nacional, dado que la lucha contra el imperialismo es el único factor capaz de aglutinar a toda la sociedad en torno al proyecto revolucionario.

- El ascenso revolucionario crea las condiciones para el surgimiento de la vanguardia.

- La vanguardia está representada por una organización (las FLN) que debe prepararse política y militarmente para dirigir el proceso revolucionario y garantizar su éxito.

- La organización debe crecer hasta convertirse en un ejército popular. Cuando el pueblo se insurreccione, la vanguardia lo dirigirá. Las FLN no se pensaban como las iniciadoras de la revolución, sino como la organización que esperaría al estallido popular, con todos los preparativos listos, aún si la espera era larga, como en efecto lo fue (Le Bot, 1997: 124).

- Pase lo que pase, tarde lo que tarde y, pese a las derrotas momentáneas, la victoria total del movimiento revolucionario es inevitable. ${ }^{11}$

Aún después de 1974, el grupo mantuvo un pronóstico pétreo respecto a la viabilidad de la revolución socialista y eso le permitió sobrevivir una y otra vez tanto a los embates represivos como a la reforma política de 1977, con la que el gobierno permitió la participación electoral de los partidos de la izquierda moderada, a los que paulatinamente se sumaron militantes que provenían de las guerrillas (Rodríguez Araujo, 1997). Las FLN se mantuvieron completamente al margen de este proceso, al que descalificaron categóricamente (Tello, 2001: 92). En entrevista con la autora, la exmilitante "María" rechazó las acusaciones de esa izquierda "asimilada" acerca de que los partidarios de la lucha armada fuesen unos ultraizquierdistas desfasados:

... a principios de los ochenta no éramos los únicos que peleábamos con las armas por el socialismo o la liberación nacional. Ahí estaban los salvadoreños, los guatemaltecos, los nicas, los palestinos... y otros, y la revolución cubana seguía siendo una esperanza que nos alimentaba. ${ }^{12}$

Desde su fundación, el objetivo central de las FLN había sido la creación de un núcleo armado. Su primer experimento foquista cobró vida en 1972 en la Selva Lacandona bajo el nombre de Núcleo Guerrillero Emiliano Zapata (NGEZ), pero fue descubierto y suprimido a través de la Operación Diamante, el primer operativo contrainsurgente en las Cañadas, llevado a cabo en 1974. El nombre de Emiliano Zapata había sido elegido en homenaje al "héroe que mejor simboliza las tradiciones de lucha revolucionaria del pueblo mexicano", y al parecer desde entonces se adoptó como el nombre fijo para el primer brazo armado rural del sureste (FLN, 1980). Entre 1975 y 1980 hubo nuevos intentos de crear un foco insurreccional, pero todos se vieron interrumpidos por la caída accidental de militantes a manos de las fuerzas del orden.

A partir del triunfo de la revolución sandinista en 1979 y la "ofensiva final" del Frente Farabundo Martí de Liberación Nacional de El Salvador en 1981, los militantes de las FLN abandonaron definitivamente el paradigma foquista de la creación de una vanguardia armada de combatientes ejemplares y lo sustituyeron por el de la guerra popular prolongada o de liberación nacional, inspirado en el marxismo vietnamita, el cual ponía énfasis en la creación de las bases de apoyo en el medio rural. ${ }^{13}$ 
De acuerdo con el análisis que las FLN hicieron de la historia de México, los campesinos habían demostrado ser la única clase social revolucionaria a consecuencia del atraso económico derivado del colonialismo y el imperialismo (Mario Marcos, 2007). Si bien era correcto plantear que en el campo había mejores condiciones para iniciar el proceso revolucionario por la predisposición de los campesinos, éstos se encontraban en proceso de desintegración como clase y no bastaba su participación para ganar, pues sólo aportaban el 6\% del PIB y el gobierno no tendría reparos en exterminarlos. Por tanto, sólo la alianza entre campesinos, obreros y sectores progresistas de la burguesía daría una dimensión nacional a la lucha revolucionaria. ${ }^{14}$ Por razones estratégicas relativas al establecimiento del teatro de operaciones, el reclutamiento de los futuros soldados del ejército popular en el medio rural se convirtió en una prioridad. A partir de 1978 las FLN iniciaron acercamientos con campesinos en distintos puntos del país, pero se centraron en Chiapas porque, de acuerdo con su diagnóstico:

Los habitantes de aquellas lejanas serranías vivían en un estado tal de explotación y miseria, de insalubridad e ignorancia, que constituían el material idóneo para formar bases de apoyo para las actividades políticomilitares de un grupo guerrillero. Su larga tradición de lucha contra la dominación, su fuerte espíritu de colectividad - acrecentado como mecanismo de defensa contra la penetración capitalista - la feroz represión de que han sido víctimas seculares, todo, los señalaba como un sector que tiene un mundo que ganar con la revolución socialista, y que no tiene nada que perder más que su miseria (Nepantla, no. 9, 1980: 10). ${ }^{15}$

Además, de acuerdo con el mismo artículo, en el terreno geoestratégico la cercanía del estado con el Istmo de Tehuantepec constituía una característica natural del territorio favorable a una división del país que permitiera consolidar una zona liberada con vistas a ser conectada con Centroamérica, especialmente con Guatemala, Nicaragua y El Salvador, que atravesaban por procesos insurreccionales. Por tanto, no hubo ninguna duda en cuanto a hacer de la Selva Lacandona la zona de operaciones.

He puesto en el tapete de la discusión los factores explicativos más importantes para entender la fundación y el impulso de las FLN, no obstante, cabe preguntarse si pueden servir también para comprender la radicalización de un sector del movimiento indígena chiapaneco y su alianza con los guerrilleros mestizos.

\section{La primera alianza entre las FLN y los campesinos radicalizados}

El contexto en el que se fundó el EZLN en 1983 era infinitamente complejo debido a la diversidad de actores políticos, religiosos y étnicos que penetraron en las distintas regiones de Chiapas. Contrariamente a los supuestos de quienes han hecho de Chiapas una especie de metonimia del neozapatismo, las FLN sólo pudieron hacer labores de reclutamiento en tres regiones: el Norte, la Selva Lacandona y Los Altos. Más allá de sus especificidades, todas ellas tenían en común el atravesar por procesos migratorios, con la consiguiente lucha por la tierra y contra los caciques o caxlanes que la acaparaban. ${ }^{16}$

Las FLN pensaban que había una asociación mecánica entre el grado de pobreza (condición objetiva permanente) y el potencial revolucionario (condición subjetiva que se construye políticamente). No obstante, basta una revisión somera de la situación de los grupos campesinos para percatarse de que no todas las comunidades fueron propensas a organizarse. Además, los indígenas, que compartían una condición estructural de dominación económica, social, étnica y cultural, dividieron su participación en función de las opciones político-ideológicas que descubrieron a través de interacciones con distintos agentes externos, los cuales 
estaban representados por la Confederación Nacional Campesina (CNC) del PRI y un sinnúmero de grupos de la izquierda legal, independiente y clandestina (García de León, 2002).

A diferencia de los militantes de las FLN, que provenían en su mayoría de la clase media profesionista y universitaria, los campesinos sí tenían una motivación económica que definía su involucramiento político. No obstante, aún cuando la lucha agraria era una cuestión de sobrevivencia, hubo miles de campesinos indígenas que optaron por no tener ningún tipo de participación. Por consiguiente, la idea de que los indígenas son rebeldes por naturaleza, que el espíritu de lucha les es inherente desde los tiempos de la conquista o que se encuentran en resistencia permanente, está muy alejada de la realidad y se debe descartar como explicación del reclutamiento campesino de las FLN-EZLN. ${ }^{17}$

Si bien es cierto que algunos pueblos indios experimentaron rebeliones, revueltas y motines entre el siglo XVII y la primera mitad del XX, no se puede generalizar esa condición a todos los demás puesto que éstos tuvieron un carácter muy localizado. ${ }^{18}$ Así también, quienes optaron por una militancia armada durante las últimas décadas del siglo XX fueron una minoría dentro del gran mosaico de las luchas sociales en Chiapas. En esta etapa, la lucha armada no era ajena al imaginario colectivo indígena, pero no era lo central dentro de sus repertorios de lucha. ${ }^{19}$ Además, mientras las rebeliones históricas que se citan con más frecuencia, como la de Cancuc en 1712 y la de Cuscat en 1868-69, tuvieron un carácter político-religioso, la de 1994 sería la primera en sostener demandas fundamentalmente seculares.

Pese a ser uno de los ejes rectores de la historia chiapaneca reciente, la lucha por la tierra no puede explicar por sí sola cómo se generó la acción colectiva insurgente, por lo que hay que analizar otras variables. Cuando las FLN regresaron a Chiapas en 1978 para establecer una base que impulsara el reclutamiento campesino, el campo político estaba ocupado por actores muy diversos (Le Bot, 1997: 106). La presencia estatal en Chiapas era muy débil y las oligarquías regionales eran mucho más poderosas que cualquier institución. Al menos hasta la década de los cuarenta, los indígenas de los diferentes grupos étnicos habían estado más o menos aislados y sin aliados externos, pero el escenario cambió con la irrupción de iglesias protestantes de origen estadounidense, a las que siguió, a comienzos de los sesenta, una compenetración más grande de la diócesis de San Cristóbal con el territorio bajo su jurisdicción (Meyer, 2000). Esta diócesis era una de las más avanzadas de la República, ya que tanto el obispo Samuel Ruiz García como sus colaboradores estaban influidos por la teología de la liberación y actuaban en sincronía con el aggiornamento de la Iglesia católica romana (Ríos, 2000).

Aunque se ha escrito mucho al respecto, sería una grave omisión no mencionar la importancia que tuvo el llamado Congreso Indígena, que se realizó en 1974 bajo auspicio del gobierno estatal para conmemorar los quinientos años del natalicio de Fray Bartolomé de las Casas (García de León, 2002; Morales Bermúdez, 2005). A partir de 1973, la diócesis de San Cristóbal de Las Casas fue la encargada de organizar y preparar a los 1.230 delegados de 327 pueblos de las etnias tsotzil, tseltal, chol y tojolabal, quienes presentaron ponencias sobre los problemas de salud, vivienda, educación y tierra. Aún cuando el Congreso no tuvo consecuencias programáticas, sirvió para que las comunidades se reconocieran como sujetos de una problemática común, hicieran diagnósticos de su situación, buscaran formas de coordinarse en lo sucesivo y generaran sus propios liderazgos. Asimismo, este hecho propició que la diócesis de San Cristóbal de Las Casas invitara a grupos como Unión del Pueblo (UP) y posteriormente a Línea Proletaria (LP) — ambos de ideología maoísta - a hacer trabajo organizativo entre las comunidades.

Coincido con los autores que recusan la idea de que el trabajo pastoral de concientización de los campesinos, a través de la "teología india", condujera 
linealmente a la lucha armada (Meyer, 2000; Ríos 2000), puesto que exactamente el mismo discurso fue utilizado por algunas comunidades para rechazar esa vía. ${ }^{20}$ Lo que ocurrió es que, a medida que las posiciones de los religiosos liberacionistas y de los militantes políticos convergían en el objetivo de que los indígenas se emanciparan, éstos no encontraron contradicción entre la palabra de Dios y las armas, a las que en algún momento llegaron a considerar como un mecanismo efectivo de liberación. Ahora bien, ¿cómo se llegó a tal convencimiento?

Hacia 1978, las FLN instalaron una casa de seguridad en San Cristóbal de Las Casas con la intención de establecer una plataforma de trabajo comunitario a través de brigadas de alfabetización, primeros auxilios, vacunación, preparación de alimentos enriquecidos, etcétera, a partir de la cual pudieran relacionarse con las comunidades marginadas del valle de Jovel..$^{21}$ A través de la exploración de sus redes de contactos, los militantes lograron establecer relaciones con campesinos de los municipios de Sabanilla y Huitiupán. La reconversión productiva de las fincas de la región Norte del cultivo de café a la ganadería fue relativamente tardía respecto a otras regiones, por eso el número de peones liberados y sin tierras era muy alto y había intensos conflictos agrarios (Renard, 1997; Pérez, 1989; Toledo, 2002).

El nivel de polarización social o, si se puede decir, de agudización de la lucha de clases, hizo de esta zona un lugar atractivo para los miembros de la Central Independiente de Obreros Agrícolas y Campesinos (la CIOAC del Partido Comunista Mexicano) y los maoístas, entre otros grupos de menor perfil. Unos y otros impulsaron diversas iniciativas para dotar de formación política a la población, especialmente a los jóvenes, lo cual repercutió favorablemente en los esfuerzos autoorganizativos de varios ejidos (Pérez, 2004). Asimismo, las comunidades más organizadas echaron mano de formas de acción directa, como las invasiones de fincas, e incluso llegaron a secuestrar a un cacique. No obstante, lo único que el gobierno estaba dispuesto a conceder era la colonización de la Selva Lacandona, en el extremo sur de la cañada de San Quintín, la cual ya había sido aceptada por numerosos contingentes de la región a lo largo de la década de los sesenta pese a la inmensa lejanía de la tierra prometida.

El 10 de junio de 1977 se desencadenó una represión de gran magnitud en Simojovel, Huitiupán y Sabanilla a cargo de la XXXI Zona Militar, finqueros armados y policías judiciales del estado: dieciséis ejidos fueron atacados, las tierras invadidas fueron desalojadas, las casas y los edificios públicos, saqueados e incendiados, doscientas cincuenta personas detenidas y el saldo rojo fue de una docena de muertos, más de sesenta heridos, decenas de torturados y mujeres violadas (Pérez, 1989). La brutal embestida generó un gran resentimiento entre la población y no sería exagerado decir que fue el germen de la lucha armada en el ejido Lázaro Cárdenas.

Lázaro Cárdenas era una pequeña comunidad tsotzil en una zona predominantemente chol, de menos de trescientos habitantes, perteneciente al municipio de Huitiupán, que desde 1940 estaba luchando por regularizar su situación agraria y en la que había habido una importante labor organizativa previa y posterior al Congreso Indígena. Asimismo, había sido uno de los ejidos más activos en las invasiones y sus líderes estaban a favor de la acción directa y la autodefensa, por lo que se deslindaron de los comunistas y los maoístas, a quienes criticaban por su tendencia a negociar con las autoridades a espaldas del movimiento (Renard, 1997).

El ejido Lázaro Cárdenas se había mostrado como uno de los más activos políticamente y el más radical, por lo que las FLN valoraron que era un terreno abonado para hacer labores de reclutamiento. Probablemente hacia 1978, la organización logró captar a "Paco" en sus filas - por alguna razón él escribió en Nepantla que había sido en marzo de 1980, pero esa fecha no coincide con otros testimonios-. A sus escasos 22 años este dirigente tsotzil cercano a la diócesis de San Cristóbal de Las Casas, había encabezado varias tomas de tierras y se convertiría en un enlace decisivo entre las FLN y el 
mundo indígena. En un testimonio "Paco" reveló: "nos dieron contacto con unos compañeros que hablaban sobre la lucha armada, que es las FLN y nos dio mucho gusto conocerlos, porque de por sí lo pensamos que la solución definitiva de las luchas es la lucha armada" (Nepantla, 1981, citado en Tello, [2005]: 93). Al parecer, las únicas condiciones de "Paco" eran que se respetara la religión católica que profesaba y que el trato a los indígenas fuera igualitario.

Como es propio de la vida comunitaria, "Paco" no tomó solo la decisión de incorporarse, sino que compartió el secreto con algunos de sus familiares más cercanos y los convenció de ser reclutados también. Sin embargo, "Paco" era una figura muy visible y no era viable que pasara a la clandestinidad, por lo que el acuerdo al que llegaron las FLN y la familia de "Paco" fue que, en vista de que los mayores no podían dejar de trabajar la tierra y sostener la lucha pública, la organización se llevaría a los menores para formarlos en las ciudades como cuadros técnicos o profesionales de la guerrilla. ${ }^{22}$ Éstos, al ser la generación directamente afectada por la falta de tierras, quizá no tuvieron objeciones para irse a vivir a las casas de seguridad urbanas. El primer grupo de reclutas estaba compuesto por aproximadamente ocho adolescentes de entre once y catorce años que, con el paso del tiempo, aprenderían adecuadamente las cuestiones ideológicas y políticomilitares y serían los primeros indígenas en tener cargos de responsabilidad al interior de las FLN y cargos militares en el futuro EZLN.

En otra parte he analizado con detenimiento el reclutamiento indígena (Cedillo, 2010), por lo que sólo quisiera resaltar mi conclusión respecto a por qué los campesinos de Lázaro Cárdenas aceptaron ingresar a las FLN. En principio, es visible que el núcleo original contaba con una tradición familiar-comunitaria de lucha y vio en la vía armada la posibilidad de resolver las demandas de la comunidad de forma definitiva. En segundo lugar, las largas décadas que la comunidad había pasado luchando por la tierra, así como la magnitud de la represión, habían radicalizado a los elementos más activos forjándoles un sentido de autodefensa. En tercer lugar, el choque cultural entre el mundo indígena y el mestizo llevó a los jóvenes a tener una percepción sobredimensionada de las FLN, al visualizarlas como una organización con los recursos -materiales, militares, informativos, etcéterasuficientes para lograr sus metas revolucionarias, conquistar la igualdad social y zanjar el abismo que mediaba entre indios y ladinos pues, de hecho, los reclutas obtenían una movilidad social de facto al entrar a la organización. En efecto, aunque las FLN tuvieran una infraestructura modesta, contaban con una serie de dispositivos tecnológicos que los indígenas, que ni siquiera tenían luz eléctrica en su comunidad, desconocían por completo. Finalmente, el acierto de las FLNfue, a diferencia de su experiencia con el NGEZ cuando se aproximaron a indígenas aislados del mundo exterior, que en el Norte contactaron a grupos previamente politizados y movilizados por otros actores, como la diócesis de San Cristóbal de Las Casas y las organizaciones de izquierda. No obstante, cabe señalar que los únicos reclutamientos exitosos se hicieron entre familiares de "Paco" en un par de ejidos de Huitiupán y Sabanilla, por lo que la incidencia de las FLN en la región Norte fue prácticamente nula durante este periodo.

Por lo que respecta al análisis de la acción colectiva, resulta evidente que, en un contexto de problemas estructurales, las comunidades indígenas tuvieron respuestas diversificadas. Se pueden observar los mismos elementos analizados previamente circulación de ideologías, competencia hegemónica, aprovechamiento de redes formales e informales, efectos de la represión de alto impacto en la radicalización-, pero la principal diferencia es que el sujeto de esta trama tiene una identidad comunitaria y étnica a partir de la cual entran en juego otra cosmovisión y otros valores identitarios que valdría la pena analizar en detalle en otra ocasión. ${ }^{23}$ 


\section{La llegada de las FLN a las Cañadas y la fundación del EZLN}

La importancia de Lázaro Cárdenas no sólo reside en haber sido la cuna del reclutamiento indígena, sino en el hecho de que los reclutas del núcleo originario abrieron a las FLN sus redes familiares en las Cañadas en un momento en que esta región estaba en vías de representar un caso único en Chiapas, y probablemente en el país, de cohesión multiétnica, voluntad de unidad social y participación política masiva. El cuádruple alineamiento: étnico, social, político y religioso, derivó en la creación de organizaciones campesinas fuertes e independientes del corporativismo priista.

Tanto en la región Norte como en las Cañadas, las FLN tuvieron que pasar por el filtro de la Iglesia católica. A pesar de que monseñor Samuel Ruiz era el único interlocutor aceptado por el Estado para atender algunas demandas indígenas -especialmente en lo tocante a violaciones graves a los derechos humanos-, como organismo, la diócesis de San Cristóbal de Las Casas no estaba alineada con las elites e hizo lo posible por mantener su autonomía, razón por la cual las FLN la veían con agrado. De esta manera, cuando "Paco" informó al obispo de la presencia de los guerrilleros, éste los mandó llamar. De acuerdo con el testimonio de "María": "Se le dijo que estábamos por la lucha armada y él contestó que no se opondría a las decisiones de los indígenas, mientras no involucráramos a las comunidades eclesiales de base en la guerra". ${ }^{24}$

A manera de especulación se puede suponer que la diócesis de San Cristóbal de Las Casas dejó actuar con libertad a las FLN a condición de que respetaran el trabajo pastoral y la autoridad del obispo y no demandaran que la diócesis de San Cristóbal de Las Casas se integrara al aparato militar. Esta libertad de acción contemplaba también el que las FLN pudieran reclutar a líderes indígenas que ocupaban cargos tanto religiosos como políticos en las comunidades de la selva: los llamados tuhuneletik o diáconos indígenas. Lo más probable es que la contribución específica de la diócesis de San Cristóbal de Las Casas a la fundación del EZLN no fuera material ni ideológica: lo que se brindó fue la permisividad para que, a partir de 1983, los guerrilleros se establecieran en las Cañadas con el apoyo de los indígenas católicos reclutados.

Desde 1978, las FLN empezaron a hacer un trabajo de exploración de los movimientos campesinos para filtrarse lentamente y, a través de ellos, crear sus propias estructuras de movilización; la maniobra rindió frutos en Lázaro Cárdenas y sería exitosa también en la cañada de San Quintín. Sin embargo, las FLN no fueron una organización oportunista que se montara en el trabajo de otros para crecer, como lo han planteado autores como Legorreta (1998) y Estrada (2007). Su estrategia consistió en reclutar selectivamente a los líderes para que éstos, a su vez, escogieran a los miembros de sus comunidades que pudieran ser afines a una militancia armada. Fueron, pues, los indígenas y no las FLN los que llevaron a cabo el reclutamiento.

El quid de la lucha agraria en la Selva Lacandona era el rechazo del gobierno federal a formar nuevos ejidos y regularizar y ampliar los existentes. En 1972, por decreto presidencial, se creó la Comunidad Lacandona y se entregó a 60 familias caribes una extensión de 614,321 hectáreas de la Selva Lacandona (De Vos, 2002). El objetivo era cerrar el ciclo de colonización de la selva y dejar el extenso territorio en manos de compañías explotadoras de maderas finas, sin tomar en cuenta ni a los 38 ejidos legalmente constituidos, ni las solicitudes de tierras en curso. En 1976, 21 ejidos aceptaron su reubicación, pero en los años sucesivos los ocho restantes se enfrentaron a las brigadas de la Secretaría de la Reforma Agraria que llegaron a realizar los deslindes. En 1977, en este clima de zozobra y confrontación, tuvo lugar una masacre de policías en Nueva Providencia, valle de San Quintín (De Vos, 2002). Aunque frecuentemente se cita este episodio como antecedente del neozapatismo, a los protagonistas no se les debe buscar en la Nueva Providencia ni en San Quintín, ya que terminaron 
en las filas de la CNC-PRI, sino en los ejidos más radicalizados, como Emiliano Zapata y Tierra y Libertad. Sin duda, ahí quedó gente que mantuvo el recuerdo de una acción armada triunfal que debió resonar con más fuerza en 1983, cuando llegaron hombres y mujeres a hablarles de la conveniencia de tomar las armas.

El gobierno federal pasó por alto estos conatos de violencia dada su infinita desconsideración hacia los pueblos indios. Así, en 1978, se cernió una nueva amenaza sobre las comunidades cuando otro decreto presidencial creó la Reserva Integral de la Biósfera de Montes Azules (RIBMA), un área natural protegida con una extensión de 331,200 hectáreas que se superponían en parte a la Comunidad Lacandona y que afectaban nuevos terrenos pertenecientes a 26 comunidades más. Los campesinos tenían que luchar entonces no contra una, sino contra dos "brechas". Esta amenaza estimuló poderosamente la autorganización campesina.

Las FLN no tuvieron ninguna conexión directa ni indirecta con la Unión de Ejidos Quiptic Ta Lecubtesel, la primera organización de masas que fue formada en la Selva Lacandona en 1975 con el apoyo de la UP -conocidos como los "chapingueros" por su origen universitario- - Tampoco se relacionaron con LP, cuyos miembros arribaron a las Cañadas en 1977, se fusionaron con la UP y promovieron la organización de la Unión de Uniones Ejidales y Grupos Campesinos Solidarios de Chiapas (UU), que representaba a doce mil familias de ciento ochenta comunidades y quince municipios y se convirtió en la organización independiente más fuerte del estado al resistir las presiones de incorporarse a la CNC (Legorreta, 1998; De Vos, 2002). De acuerdo con García de León:

Línea Proletaria y sus derivados lograron consolidar un amplio movimiento de uniones de ejidos y sociedades de crédito en Chiapas, desarrollando formas de democracia interna en la toma de decisiones de los propios núcleos campesinos, principalmente en la selva. Es más, sin ese antecedente organizativo, valioso y perdurable, el cual se unía tanto a la tradición local de resistencia como al trabajo religioso de los catequistas, la misma rebeldía en la selva no hubiera podido desarrollarse con tanta efectividad y sigilo tantos años después. Pero podemos decir también con toda claridad... que esta organización [...era] un ambicioso proyecto del Estado para neutralizar la radicalidad de varias movilizaciones obreras y campesinas que brotaban en el país... (García de León, 2002: 194).

Es hasta cierto punto irrebatible que la semillaideológica, la familiarización con un lenguaje de izquierda radical y ciertas prácticas asamblearias apropiadas por campesinos de diversas regiones, no fueron obra de la "teología india" de la diócesis de San Cristóbal de Las Casas, ni de las tradiciones "democráticas" mayas, sino de los maoístas. Sin embargo, a comienzos de los ochenta, las FLN y LP tenían proyectos paralelos y hasta antagónicos, y fueron percibidas como dos opciones distintas por los campesinos. Sería un error desestimar la importancia de la primera generación de reclutas indígenas de las FLN, adolescentes que crecieron en casas de seguridad sin haber pasado por las filas de LP y que tendrían un papel protagónico en el crecimiento de la organización a partir de 1984.

En 1983 la UU, que detentaba la hegemonía en la selva, se partió en dos por el choque entre quienes mantenían la demanda por la tierra y los que sólo buscaban obtener créditos para comercializar las cosechas, desactivando los conflictos agrarios e insertando a los indígenas en la lógica del mercado para que pudieran ingresar a la modernidad desarrollista. En consecuencia, los asesores maoístas fueron expulsados de las Cañadas, aunque nuevos elementos regresaron poco después (De Vos, 2002). Así, el arribo de las FLN a las Cañadas coincidió con cierta percepción de agotamiento político de la lucha legal, lucha que los guerrilleros se encargaron de explotar.

Revista LiminaR. Estudios Sociales y Humanísticos, año 10, vol. X, núm. 2, julio-diciembre de 2012, San Cristóbal de Las Casas, Chiapas, México. ISSN: 1665-8027 
Las FLN penetraron en la selva con el objetivo involuntariamente pospuesto durante nueve añosde formar un núcleo guerrillero que fuera el embrión del ejército popular, pero a diferencia del NGEZ, en 1983, no se insertaron como un grupo exógeno sino que se apoyaron en sus cuadros indígenas y sus redes. Familiares de "Paco" en Lázaro Cárdenas y El Calvario - ejidos vecinos, separados por una división administrativa artificial entre Huitiupán y Sabanilla-, sugirieron a los guerrilleros que se adentraran en la selva por la cañada de San Quintín hasta llegar a los distantes ejidos de Emiliano Zapata y Tierra y Libertad, donde vivían parientes suyos. ${ }^{25}$ De Vos no se equivocó al sugerir que la ruta de penetración de las FLN fue idéntica a la ruta de colonización abierta por los fundadores de ambos ejidos (De Vos, 2002).

Emiliano Zapata fue fundado en 1968 por el famoso líder agrario Rosario López Ovando — asesinado en 1978 - y por tsotziles y choles cuyos hijos se movieron hacia el sur y conformaron Tierra y Libertad en 1971. Además, tras los acontecimientos de 1977 en la región Norte se incrementó el flujo hacia el sur, por lo que la nueva población que llegó a la cañada de San Quintín ya estaba politizada en algún grado (De Vos, 2002). Así, si bien la elección del lugar por parte de las FLN era geoestratégica, también se consideraba que había una disposición combativa de la población de la zona. Cabe aclarar que Emiliano Zapata contaba con una resolución presidencial desde 1969 y Tierra y Libertad la obtuvo en 1985; ambos ejidos también tenían una posesión ilegal de tierras y se encontraban en una zona gris de la RIBMA.

En diferentes comunicados y entrevistas, el subcomandante Marcos ha expuesto su esbozo por etapas del proceso organizativo del EZLN entre 1983 y 1985, que podría resumirse en: 1) selección de participantes e inspección de las condiciones del lugar; 2) implementación en la zona; 3) supervivencia y 4) primeros contactos con las comunidades (Le Bot, 1997; Subcomandante Marcos, 2010). Desde 1982 la Dirección Nacional dispuso que dos responsables nacionales,
"Germán” y "Elisa”, el militante profesional "Rodolfo" y tres insurgentes indígenas, de alias "Javier", "Jorge" y "Frank", quienes tenían cinco años viviendo en casas de seguridad y quizá eran los cuadros mejor entrenados, hicieran el viaje fundacional a la selva. En la montaña de Chuncerro, próxima a la Laguna de Miramar, sin ceremonia ni protocolo de por medio, el 17 de noviembre de 1983 instalaron el primer campamento del Ejército Zapatista de Liberación Nacional al que denominaron "La garrapata". Al parecer, permanecieron en la zona alrededor de seis meses, cambiando de posición, pero en este lapso hubo dos elementos que "subían y bajaban" a la ciudad para realizar labores de correo y abastecimiento, a la vez que llegaron otros indígenas y mestizos. ${ }^{26} \mathrm{De}$ acuerdo con "Daniel", que subió a la montaña en 1985: "la idea era llegar a la selva, instalarse, entrenarse, dominar la selva, o por lo menos que la selva te aceptara, para luego de ahí salir e ir contactando gente" (Rico y De la Grange, 1999). Las comunidades indígenas tsotziles y choles de la cañada de San Quintín, conformadas por migrantes que tenían muy poco tiempo rehaciendo sus identidades colectivas, fueron las primeras con las que se llevaron a cabo estos acercamientos.

La etapa de preparación selectiva en la montaña y primeros contactos, a la que el subcomandante Marcos caracterizó sarcásticamente como la del "foco fundido", habría durado hasta 1985, cuando se ganaron algunas comunidades enteras y los insurgentes podían entrar libremente a sus poblados dando por concluida la fase de implantación del núcleo guerrillero (Le Bot, 1997: 132143). Entonces se habría producido, a decir de Marcos, una "primera derrota" frente a los indígenas, cuando descubrieron "que el EZLN no tiene nada qué hacer" más que aprender y subordinarse a ellos, dándose pie a la indianización del proyecto armado. ${ }^{27}$

Entre 1983 y 1985, la subvanguardia indígena compuesta en su mayoría por el núcleo original de Lázaro Cárdenas - sirvió como intermediaria para iniciar un reclutamiento selectivo entre los jefes de las comunidades. El éxito de estos intermediarios se vio 
reflejado en que Tierra y libertad se convirtiera en el primer pueblo base de apoyo neozapatista en 1984. El subcomandante "Marcos" advierte que el encuentro inicial entre el EZLN y los jefes — quienes por lo general combinaban el liderazgo político y religioso-, fue producto de una necesidad de autodefensa de las comunidades, en un sentido de "interés práctico, de sobrevivencia" ante la amenaza de ser desalojados por la brecha lacandona (Le Bot, 1997: 143). Sin embargo, las FLN-EZLN, paulatinamente, les plantearon que no bastaban la autodefensa ni los proyectos reformistas, sino que era necesaria una salida revolucionaria que produjera cambios de raíz y acabara de una vez para siempre con el capitalismo y sus males. Al margen de que algunos indígenas hayan interiorizado este discurso y otros no, sin duda su inscripción en la acción colectiva insurgente estuvo en buena medida determinada por la amenaza de perder la fuente de su sustento e identidad, así como por su necesidad de hacer frente a la violencia de los caxlanes.

El pacto entre las FLN y los autodenominados "príncipes de la selva" fue semejante al acuerdo que habían hecho con "Paco": puesto que éstos no podían pasar a la clandestinidad por la naturaleza pública de su quehacer, la organización se llevaría a sus hijos para formarlos en las ciudades y los reinsertarían en la selva para reclutar y adiestrar a otros cuadros potenciales.

Mi conclusión respecto al proceso analizado es que el EZLN pudo penetrar las Cañadas, no sólo por la permisividad de la diócesis de San Cristóbal de Las Casas y la salida de los competidores políticos, sino sobre todo por decisión de la subvanguardia indígena y de los "príncipes de la selva". Cabe hablar de la fundación de dos EZLN: uno, que nace en 1983 como producto de la tenacidad político-ideológica de los militantes de las FLNy de la percepción del agotamiento de la lucha civil por parte de un grupo de indígenas del Norte con una larga trayectoria de movilización; y otro que se gesta en la segunda mitad de la década de los ochenta como resultado de la autonomía organizativa de las comunidades, al considerar que la oferta política de la vía legal era insuficiente y había que transitar, simultáneamente, el camino de la lucha armada. Ambas agendas entraron en un proceso dialéctico de convergencias y divergencias que culminó con la rebelión del año 1994.

\section{Conclusiones}

El objetivo de analizar la trayectoria de las FLN-EZLN ha sido demostrar que la aparición del EZLN no era algo que tuviera que ocurrir fatalmente debido a las contradicciones sistémicas, como la articulación de las formas precapitalistas de Chiapas con la dinámica capitalista nacional e internacional, o la transición del modelo populista al neoliberal — proceso que ocurrió simultáneamente y que de ningún modo fue causante de la llegada de las FLN a Chiapas o de que el EZLN hubiera crecido entre 1984 y 1988-. Hay que reconocer que la fundación del EZLN fue parte de un proyecto revolucionario de largo alcance, motivado por la postura ideológica de un grupo que adoptó la vía armada en un contexto adverso, después de la reforma política de 1977, cuando casi nadie pensaba que pudiera prosperar. Sin embargo, sería incorrecto decir que el EZLN se formó por el voluntarismo, el capricho o la fiebre guerrillera característicos de los años sesenta y setenta o, peor aún, que el EZLN de 1994 era ideológicamente el mismo de 1983, interpretaciones derivadas, en buena medida, de la obra de Tello.

Podemos advertir que tanto en el caso de la fundación de las FLNy como del EZLN, la acción colectiva insurgente fue resultado, no de las contradicciones estructurales del sistema en sí, sino de la manera en que fueron interpretadas a través de ideologías revolucionarias universalizadas. Los alcances de tales ideologías dependían de la capacidad de las organizaciones para construir o aprovechar las redes sociales formales e informales, así como de los resultados coyunturales de la competencia hegemónica. Asimismo, 
la violencia política tuvo más impacto en los procesos de radicalización de los militantes que la violencia cotidiana del capitalismo, traducida en explotación y precariedad.

En el proceso de constitución del sujeto político étnico se observan los mismos elementos causantes de la acción colectiva, aunque la asociación entre la tierra y la identidad y, sobre todo, la amenaza a esta identidad, más que la cuestión ideológica, fue definitoria. En la lucha, los indígenas se empoderaron, se politizaron y reclamaron un nuevo tipo de relación con el Estado que no pasara por el sometimiento o la cooptación. Al toparse con la indiferencia y la represión gubernamentales, asumieron una posición cada vez más radical y visualizaron a las FLN-EZLN como un instrumento que les permitiera hacerse ver y escuchar, o volcar la correlación de fuerzas a su favor. De esta manera, la utilización sería mutua: los campesinos aprovecharían las enseñanzas políticomilitares de los militantes del EZLN para aprender a defender sus derechos con las armas, mientras que los guerrilleros harían de ellos las bases de apoyo con las que tanto habían soñado para construir su utopía socialista. En el proceso, la subjetividad política de los indígenas adquirió modalidades distintas: algunos interiorizaron las cuestiones ideológicas y fueron leales a las metas del EZLN, mientras que otros actuaron de forma instrumental y pragmática, de acuerdo con objetivos locales.

Por todo lo anterior, mi trabajo se inscribe en una corriente que rechaza, tanto la visión esencialista de los indígenas como rebeldes por naturaleza, como la que los considera entes subordinados a agentes exógenos en busca de un mero fin material como la tierra. Además, a manera de precaución, debe señalarse que el análisis del periodo específico de la primera mitad de la década de los ochenta no puede extrapolarse a etapas posteriores.

Es importante enfatizar que, si bien la diócesis de San Cristóbal de Las Casas contribuyó a la generación del clima ideológico - al señalar a los indios como el pueblo elegido para la búsqueda de la liberación-y abrió su territorio a las izquierdas, y los maoístas brindaron cierta formación política y modelos organizativos, la posibilidad de organizar militarmente a las comunidades fue obra exclusiva de las FLN-EZLN. Esto no significa que la vanguardia mestiza haya tenido el control de todo, pues la subvanguardia indígena tuvo un papel fundamental en el proceso formativo del EZLN como mediadora de dos mundos que parecían completamente distintos. Con el ingreso de un número de indígenas que superaron por mucho a los cuadros mestizos, el EZLN caminó por otros derroteros y terminó por rebasar y minar a las FLN.

La herencia de las FLN se mantuvo presente en el EZLN a lo largo de su proceso formativo, e incluso la estrategia militar de la guerra popular de liberación nacional diseñada desde 1980 se aplicó en 1994. No obstante, a diferencia de las FLN, que fueron una organización muy rígida, sin capacidad para adaptarse a los cambios, el EZLN evolucionó constantemente. De esta manera, hubo un EZLNalimentado por comunidades indígenas que ejercían una autonomía de facto entre 1984 y 1993; otro que rompió con su organización madre y con una parte de su base indígena protagonizando la rebelión de 1994 bajo objetivos que ya no tenían que ver con la lucha por el socialismo, otro más que, con los Diálogos de San Andrés de 1995, terminó decantándose por la vía política y la demanda de reconocimiento de los derechos colectivos de los pueblos indios, entre otros más quizá. En todos estos momentos la interacción entre la dirigencia y las bases se ha dado de manera compleja y contradictoria, por lo que no se puede dar un veredicto uniforme ni calificar simplistamente al EZLN como autoritario o democrático, aún cuando en sus orígenes esta organización haya sido, en efecto, vertical y jerárquica.

En el campo de la acción colectiva insurgente, considero que entender por qué algunos indígenas que habían estado militando durante años en la clandestinidad sin una verdadera actividad militar se alzaron en armas el 1 de enero de 1994, mientras otros 
en las mismas circunstancias rechazaron dar ese paso, ameritará un esfuerzo analítico mucho más profundo que el realizado hasta ahora.

\section{Notas}

${ }^{1}$ Wickham (1998) propuso un modelo explicativo general que, aunque fue influyente en los Estados Unidos, no tuvo ninguna repercusión en el mundo académico latinoamericano. Noconozco ningún otro autor que se haya propuesto elaborar una tipología sobre las organizaciones armadas de la región, pues obras como la de Castañeda (1994) son de carácter monográfico.

2 Desde luego, esta omisión se encuentra en las obras de carácter estrictamente académico, la mayoría de las cuales se centra en el neozapatismo a partir de su aparición pública o menciona a las FLN de forma superficial, como Legorreta (1998), De Vos (2002) y Estrada (2007). Entre los trabajos no académicos, La rebelión de las Cañadas de Tello (2005 [1995]) tiene la estructura de un ensayo histórico, pero carece de rigor teórico-metodológico. Marcos, la genial impostura de Rico y de la Grange (1998) es un ensayo netamente periodístico, pero eso no lo excusa de ser poco confiable ya que no cuenta con el menor esfuerzo de verificación de fuentes.

${ }^{3}$ Basta contrastar documentos de las FLN-EZLN en los que explícitamente se menciona la lucha por el socialismo como un objetivo central (citados en Tello, 2005 [1995]: 199, 262), con los comunicados que emitió el EZLN a partir de enero de 1994, en los que no se vuelve a mencionar este punto aún cuando se preservaran algunos elementos de la retórica anticapitalista y antineoliberal (EZLN, 1994-2001). El deslinde tiene que ver tanto con la derrota ideológica del socialismo a nivel mundial, de la que las FLN tomaron nota muy tardíamente, como con el hecho de que sólo hasta después del levantamiento, el EZLN estuvo en condiciones de hacer a un lado lo que quedaba del partido de las FLN — la otra parte había dejado el grupo en enero de 1993 - para actuar con plena autonomía. No obstante, a partir de enero del año 94 el EZLN parece haberse sumido en el extravío y la reconfiguración ideológicos, de los que derivaron múltiples virajes discursivos.

${ }^{4}$ Así por ejemplo, las obras de Rovira (1994), Muñoz (2003), Castellanos (2007) e incluso Le Bot (1997) parecen muy condescendientes y poco críticas con los testimonios de los dirigentes y milicianos zapatistas a quienes tuvieron la oportunidad de entrevistar, además de no ofrecer fuentes alternativas a las orales.

${ }^{5}$ Cabe aclarar que los testimonios han sido empleados en sentido estrecho, para completar vacíos en la narración y confrontar datos obtenidos por otras fuentes. Algunos entrevistados admitieron el uso de pseudónimos y otros prefirieron que se omitiera cualquier referencia a sus personas. Tras hacer la crítica de fuentes respectiva, he optado por incluir los datos que aportaron, por ser referencias únicas a episodios desconocidos.

${ }^{6}$ Las condiciones objetivas tienen que ver con las contradicciones entre el desarrollo de las fuerzas productivas y las relaciones sociales de producción y la organización del poder político, que no se adecúan a las nuevas formas; en otras palabras, la superestructura jurídico-política no corresponde a la estructura económica. Las subjetivas están relacionadas con el nivel de conciencia, organización y determinación de las masas para la lucha (Gianfranco Pasquino, "Revolución", en Bobbio, Matteucci y Pasquino, 2000, t. 2: 1417). Considero que hay que superar tanto la visión determinista como la voluntarista en torno a la situación revolucionaria, analizar detenidamente todas las variables que intervienen y en qué casos pesa más lo objetivo que lo subjetivo o viceversa, así como distinguir claramente las revoluciones que provocan cambios de régimen de las que causan un cambio total de sistema socioeconómico.

${ }^{7}$ El marxismo consideraba que la ideología pertenecía al orden de la superestructura y se irradiaba a través de los aparatos ideológicos del Estado (Althusser, 
2008 [1970]). El debate sobre la ideología es de una complejidad que rebasa los límites de este artículo, pero, para los fines de mi argumentación, considero las ideologías como resultado de los procesos formativos de las identidades colectivas, que se difunden a través de estructuras - en sentido genérico, no marxistay que operan y surten un efecto diferenciado en la subjetividad de los receptores.

${ }^{8}$ Dentro del modelo del proceso político, se conoce como estructura de oportunidades políticas (EOP) al "grado de posibilidades que los grupos tienen de acceder al poder e influir sobre el sistema político". Las dimensiones relevantes de la EOP se pueden resumir en cuatro puntos: 1) el grado de apertura del sistema político institucionalizado; 2) la estabilidad en las alineaciones de las elites; 3) la posibilidad de contar con el apoyo de esas elites; y 4) la capacidad estatal y su tendencia a reprimir a los movimientos sociales (McAdam, 1999: 50-55). Recuso la utilización del concepto de EOP porque puede generar una falsa percepción de contextos en los que por lo general están presentes las constricciones, las amenazas y la polarización sociopolítica como factores que incitan a la acción colectiva, además de que, como señala Tarrow (1997), las oportunidades son situacionales, no estructurales.

${ }^{9}$ En conversaciones que sostuve con exmilitantes de distintos grupos, casi todos referían causas políticas más que económicas al explicar sus motivaciones personales para participar en la lucha armada. Una de las paradojas de este proceso es que los estudiantes habían sido uno de los sectores beneficiados por el desarrollismo, el cual permitió la masificación de las universidades y la creación sostenida de fuentes de empleo, no obstante, los estudiantes radicalizados fueron los fundadores de la mayoría de las organizaciones armadas.

${ }^{10}$ La reconstrucción detallada de tales acontecimientos (Cedillo, 2008) fue posible a través de la consulta de los expedientes individuales de César Yáñez, Carlos Vives, Mario y Elisa Sáenz en el fondo DFS del AGN, así como también mediante entrevistas con algunos de sus familiares.

"I AGN, DFS, [Comunicados confidenciales a los militantes de las FLN, 1970-1980], Exp. 009-011-005, H-1-9l.

${ }^{12}$ Entrevista de la autora con "María", 17 de junio de 2009.

${ }^{13}$ Este cambio implicó ponderar la estrategia militar de la guerra de movimientos y posiciones por encima de la de guerrillas. Esto se traduciría en el hecho de que en enero de1994, pese a sus limitaciones en estrategia, entrenamiento y potencial de fuego, el EZLN peleara como ejército, con columnas, y no como guerrilla.

${ }^{14}$ Entrevista de la autora con "María", 17 de junio de 2009.

${ }^{15}$ Nepantla. Órgano de agitación y comunicación interna de las FLN, se comenzó a editar en 1979 como una revista clandestina dirigida a la formación política de los cuadros. En ella aparecen los recuentos más detallados de la historia del grupo y de sus militantes caídos en combate. Da cuenta también del corpus ideológico de la organización y permite apreciar que ningún tópico de la cultura universal de la izquierda le fue ajeno.

${ }^{16}$ Una visión más profunda de cada región se puede encontrar en De Vos (2002), Leyva y Ascencio (2002), García de León (2002) y Viqueira y Ruz (2004).

${ }^{17}$ De Vos propuso tres tipos de estrategias o repertorios empleados por los pueblos nativos a lo largo de cuatro siglos y medio de dominio colonial y neocolonial, a saber: la resistencia abierta (levantamientos armados y desplazamiento territorial estratégico), la resistencia velada (prácticas de resistencia cotidiana en el ámbito privado y ocasionalmente en el público) y la resistencia negociada (concesiones de líderes indígenas a los dominadores a cambio de privilegios) De Vos, (1995: 239). Sin embargo, hay que aceptar que los indígenas también tuvieron actitudes de resignación, fatalismo o conformismo, como cualquier colectividad humana.

${ }^{18} \mathrm{El}$ problema con las visiones esencialistas es que ponderan los momentos de crisis, conflicto y rebelión y los hacen parecer como más significativos 
que los periodos de estabilidad y colaboración entre dominadores y dominados. La obra de García de León (1985) ha contribuido en buena medida a generar esta percepción, ya que el autor considera a los movimientos sociales como los actores centrales de la historia.

${ }^{19}$ De acuerdo con "María", algunas comunidades a las que se acercaron recordaban que sus abuelos habían participado en la revolución e incluso tenían armas enterradas que databan de ese periodo. El hecho de que no las hubieran usado en combate hasta 1994, durante unos pocos días, es un dato que debe ser tomado en cuenta.

20 De acuerdo con Ríos (2000: 156) la teología india retomaba los preceptos de la teología de la liberación en torno al desmantelamiento de estructuras que estaban a favor de la dominación, pero enfocando al indígena -el pobre por antonomasia - como el sujeto de la historia. Del mundo indígena se exaltaban los valores de solidaridad, comunitarismo, igualdad y justicia social, integración con la naturaleza, amor a la "madre tierra" y el monismo - fusión de materia y espíritu-. En síntesis, este discurso ponderaba factores como la raza, la comunidad, la religión; la tradición, no sólo ajenos sino incluso opuestos al marxismo. Aunque no se hablaba explícitamente de una "teología india" a comienzos de los setenta, en 1972 la diócesis de San Cristóbal de Las Casas comenzó a esbozar la idea de una "Iglesia autóctona" y en 1975 hizo explícita su "opción preferencial por los pobres" bajo estas premisas (Fazio, 1994: 87).

${ }^{21}$ Entrevista de la autora con Elisa Benavides, febrero de 2004, ciudad de México.

${ }^{22}$ Entrevista de la autora con "María", junio de 2009.

${ }^{23}$ Aunque no es un tema que haya investigado, creo que es importante señalar que los habitantes de Lázaro Cárdenas eran descendientes de migrantes de San Juan Chamula, condenados a una nueva migración hacia la Selva Lacandona (Leyva y Ascencio, 2002: 97). Esta identidad migrante hacía de Lázaro Cárdenas una comunidad distinta a otras aledañas. Para entender la subjetividad de los habitantes de este lugar sería imprescindible hacer un estudio etnográfico o una microhistoria del ejido.

24 "María" también reveló que las FLN sólo querían trabajar en comunidades católicas porque consideraban que las demás estaban penetradas por grupos protestantes del Instituto Lingüístico de Verano, al que consideraban "un organismo encubierto de la CIA, que había ayudado a los servicios de inteligencia a ubicar y ejecutar a Yon Sosa". De este modo, existe la posibilidad de que la diócesis de San Cristóbal de Las Casas y las FLN hubieran externado su mutuo rechazo hacia los protestantes, generándose empatía ante tal convergencia.

${ }^{25}$ Entrevista de la autora con "María", junio de 2009.

${ }^{26}$ Esta versión es el resultado de la confrontación de diversas fuentes: Rico y De la Grange (1998: 167), Tello (2000: 110), Henríquez (2009), así como testimonios de exmilitantes.

27 Esta afirmación ha suscitado intensos debates. Mientras que un sector de académicos filozapatistas no cuestiona su dicho, Legorreta y Estrada han tratado de demostrar que el proyecto mantuvo la verticalidad y autoritarismo propios de un grupo guerrillero, por lo que la dirigencia zapatista siempre tuvo el control de todo. El análisis detallado del papel del grupo Slohp, sobre el que existe muy poca información, así como el de los líderes indígenas, autodenominados según el exsubcomandante Daniel como los "príncipes de la selva" (Rico y de la Grange, 1999), contribuiría a afinar nuestra visión del proceso. Mi reserva hacia la interpretación de Legorreta (1998: 187), que identifica a ciertos agentes de la pastoral como intermediarios entre los líderes indígenas agrupados en Slohp y las FLN, es que basa su relato en buena medida en el testimonio de Lázaro Hernández, que si bien fue uno de los líderes políticoreligiosos más importantes de la selva (el "príncipe" 
mayor diríamos), cambió muchas veces de bando y de versión.

\section{Bibliografía}

Althusser, Louis (2008 [1970]), La filosofía como arma de la revolución, México: Siglo XXI Editores.

Bobbio, Norberto, Nicola Matteucci y Gianfranco Pasquino (coords.) (2000), Diccionario de política, vol. 2, México: Siglo XXI Editores.

Castañeda, Jorge (1993), La utopía desarmada, México: Joaquín Mortiz.

Castellanos, Laura (2007), México armado, 1943-1981, México: Era.

Cedillo Cedillo, Adela (2008), El fuego y el silencio. Historia de las Fuerzas de Liberación Nacional Mexicanas (1969-1974), México: El autor, Tesis de licenciatura en Historia, Facultad de Filosofía y Letras/UNAM.

Cedillo Cedillo, Adela (2010), El suspiro del silencio. De la reconstrucción de las Fuerzas de Liberación Nacional a la fundación del Ejército Zapatista de Liberación Nacional (1974-1983), México: El autor, Tesis de maestría en Estudios Latinoamericanos/UNAM.

Cedillo Cedillo, Adela y Fernando Calderón, eds. (2012), ChallengingauthoritarianisminMexico.RevolutionaryStruggles and the Dirty War, 1964-1982. New York: Routledge.

Cedillo Cedillo, Adela y Ricardo Gamboa (2010), "Interpretaciones sobre los espacios de participación política después del 10 de junio de 1971 en México", en Oikión, Verónica y Miguel Ángel Urrego, (eds.) Violencia y sociedad. Un hito en la historia de las izquierdas en América Latina, México: UMSNH/COLMICH.

Chihu Amparán, Aquiles, coord. (2006), El "análisis de los marcos”, en la sociología de los movimientos sociales, México: Miguel Ángel Porrúa-CONACYT-UAM-Iztapalapa.

Ejército Zapatista de Liberación Nacional (1994-2001), Documentos y comunicados, vol. 5, México: Era.

Estrada Saavedra, Marco (2007), La comunidad armada rebelde y el EZLN: un estudio histórico y sociológico sobre las bases de apoyo zapatistas en las cañadas tojolabales de la Selva Lacandona (1930-2005), México: COLMEX.
Fuerzas de Liberación Nacional (1980), Estatutos de las Fuerzas de Liberación Nacional, 6 de agosto (mimeo).

García de León, Antonio (2002), Fronteras interiores. Chiapas: una modernidad particular, México: Océano.

García de León, Antonio (1997 [1985]), Resistencia y utopía: memorial de agravios y crónicas de revueltas y profecías acaecidas en la provincia de Chiapas durante los últimos quinientos años de su historia, México: Era.

González Casanova, Pablo (1995), "Causas de la rebelión en Chiapas", en suplemento "Perfil" de La Jornada, noviembre.

Grange, Bertrand de la y Maité Rico (1998), Marcos, la genial impostura. México: Aguilar.

Grange, Bertrand de la y Maité Rico (1999) "Entrevista con Salvador Morales Garibay", en Letras libres, 〈http://www.letraslibres.com/revista/convivio/ entrevista-con-salvador-morales-garibay> [consulta: junio 5 de 2012].

Guevara, Ernesto "Che" (1967), "Mensaje a la Tricontinental", Cuadernos de Ruedo Ibérico, 94-101, 〈http://www.filosofia.org/hem/dep/cri/ril2094.htm〉 [consulta: junio l de 2012].

Henríquez, Elio (2009), "EZLN, 26 años de historia", Cuarto poder, 17 de noviembre, 〈https://zapateando. wordpress.com/2009/11/19/ezln-26-anos-dehistoria/>, [consulta: junio 5 de 2012].

Laclau, Ernesto y Chantal Mouffe (2006 [1985]), Hegemonía y estrategia socialista. Hacia una radicalización de la democracia, Buenos Aires: Fondo de Cultura Económica.

Le Bot, Yvon (1997), El sueño zapatista. Entrevistas con el subcomandante Marcos, el mayor Moisés y el comandante Tacho, del Ejército Zapatista de Liberación Nacional, Barcelona: Plaza y Janés.

Legorreta Díaz, María del Carmen (1998), Religión, política y guerrilla en Las Cañadas de la Selva Lacandona, México: Cal y Arena.

Leyva Solano, Xóchitl y Gabriel Ascencio Franco (2002), Lacandonia al filo del agua, México: CIESAS/UNAM/ FCE. 
Mario Marcos (2007), Nada es gratuitoen la historia, México: Ediciones Rebeldía.

McAdam, Doug,John D. McCarthy y Mayer N. Zald, (eds.) (1999), Movimientos sociales: perspectivas comparadas. Oportunidades políticas, estructuras de movilización y marcos interpretativos culturales, Madrid: Istmo.

Meyer, Jean (2000), Samuel Ruizen San Cristóbal, 1960-2000, México: Tusquets Editores.

Morales, Bermúdez, Jesús (2005), Entre ásperos caminos llanos: la diócesis de San Cristóbal de Las Casas, 1950-1995, México: Juan Pablos.

Muñoz, Gloria (2003), EZLN: 20 y 10, el fuego y la palabra, México: Revista Rebeldía-La Jornada Ediciones.

Oikión, Solano Verónica y Marta Eugenia García Ugarte, (eds.) (2006), Movimientos armados en México en el siglo XX, Vol. 3, Morelia: CIESAS/COLMICH.

Pérez, Castro Ana Bella (1989), Entre montañas y cafetales: luchas agrarias en el Norte de Chiapas, México: UNAM/ IIA.

Renard, María Cristina (1997), "Movimiento campesino y organizaciones políticas. Simojovel-Huitiupán (1974-1990)", en Revista Chiapas, núm. 4, México: Era-IIE-UNAM, 〈http://membres.multimania.fr/ revistachiapas/No4/ch4renard.html> [consulta: junio 3 de 2012].

Ríos, Figueroa, Julio (2000), Siglo XX: muerte y resurrección de la Iglesia Católica en Chiapas: dos estudios históricos, México: UNAM.

Rivas, Ontiveros, José René (2007), La izquierda estudiantil en la UNAM, Organizaciones, movimientos y liderazgos (1958-1972), México: UNAM/Miguel Ángel Porrúa.
Rodríguez, Araujo, Octavio, coord. (1997), La reforma política y los partidos en México, México: Siglo XXI.

Rovira, Guiomar (1994), iZapata vive! La rebelión indígena de Chiapas contada por sus protagonistas, Barcelona: Yirus Editorial.

Subcomandante Marcos (2003), "Mensajeenviadoalarranque de la campaña EZLN:20y 10, el fuego y lapalabra”, en ‘http:// palabra.ezln.org.mx/comunicados/2003/2003_ll_10. htm> [consulta: junio l de 2012].

Tarrow, Sidney (1997), El poder en movimiento. Los movimientos sociales, la acción colectiva y la política, Madrid: Alianza.

Tello, Carlos (2005 [1995]), La rebelión de las Cañadas. México: Editorial Planeta.

Toledo, Sonia (2002), Fincas, poder y cultura en Simojovel, Chiapas, San Cristóbal de Las Casas, Chiapas, México: UNAM/UNACH.

Viqueira, Juan Pedro y Mario Humberto Ruz, eds. (2004), Chiapas, los rumbos de otra historia, México: UNAM/CIESAS.

Vos, Jean de (2002), Una tierra para sembrar sueños. Historia reciente de la Selva Lacandona, 1950-2000, México: FCE.

Vos, Jean de (1995), "Las rebeliones de los indios de Chiapas en la memoria de sus descendientes" en JaneDale Lloyd y Laura Pérez Rosales, (coords.). Paisajes rebeldes. Una larga noche de resistencia indígena, México: Universidad Iberoamericana.

Wickham Crowley, Timothy P. (1992), Guerrillas and Revolution in Latin America. A Comparative Study of Insurgents and Regimes since 1956, Princeton: Princeton University Press. 